\title{
Congenital pseudoarthrosis of the clavicle
}

INSERM

\section{Source}

INSERM. (1999). Orphanet: an online rare disease and orphan drug data base. Congenital pseudoarthrosis of the clavicle. ORPHA:66630

Congenital pseudoarthrosis of the clavicle is a rare benign condition, characterized by a painless mass or swelling over the clavicle. 